\title{
Sarcopenia in COPD patients: Prevalence, patients' characteristics and predictive factors
}

\author{
Vitalii Poberezhets ${ }^{1}$, Szymon Skoczyński², Anna Demchuk¹, Aleksandra Oraczewska², Ewelina Tobiczyk ${ }^{3}$, Yuriy Mostovoy²,
} Adam Barczyk²

\begin{abstract}
INTRODUCTION Taking into consideration multifactorial origin of sarcopenia and extrapulmonary manifestations of chronic obstructive pulmonary disease (COPD), our study aimed to determine the prevalence and predictive factors for sarcopenia among COPD patients.

METHODS We examined 190 patients with COPD in Ukraine and Poland using bioelectric impedance analysis, hand-grip dynamometry, 6MWT and several questionnaires to assess clinical characteristics of the patients.

RESULTS Sarcopenia was detected in $25.3 \%$ of all patients with COPD. There was a significant difference between patients with and without sarcopenia in age, acute exacerbations of COPD, CAT, FEV ${ }_{1}, \mathrm{BODE}$ and $\mathrm{CCl}$, Borg scope (post 6MWT), hand-grip strength, BMI, fat mass index, level of visceral fat, fat percentage, skeletal muscle index, gait speed, and 6MWT distance. According to regression analysis, factors related to sarcopenia were body mass index, visceral fat level, daily physical activity, percentage of fat and GOLD 3 airflow limitation.

CONCLUSIONS Sarcopenia affected almost every fourth COPD patient and was associated with low BMI, high level of visceral fat and percentage of body fat, limited physical activity, and severe airflow limitation.
\end{abstract}

Abbreviations 6MWT: the 6-minute walk test, BMI: body mass index, BODE index: body mass index, airflow obstruction, dyspnoea, exercise capacity index, CAT: the COPD assessment test, CCI: Charlson comorbidity index, COPD: chronic obstructive pulmonary disease, $\mathrm{FEV}_{1}$ : forced expiratory volume in one second, mMRC: modified Medical Research Council, SaO2: oxygen saturation, SGRQ: St. George's respiratory questionnaire.

\author{
AFFILIATION \\ 1 Department of Propedeutics of Internal \\ Medicine, National Pirogov Memorial Medical \\ University, Vinnytsya, Ukraine \\ 2 Department of Pneumonology in Katowice, \\ School of Medicine in Katowice, Medical \\ University of Silesia, Katowice, Poland \\ 3 Department of Respiratory Medicine, \\ Allergology and Pulmonary Oncology, Poznań \\ University of Medical Sciences, Poznań, \\ Poland
}

\section{CORRESPONDENCE TO \\ Vitalii Poberezhets. Department of \\ Propedeutic of Internal Medicine, National \\ Pirogov Memorial Medical University, 56, \\ Pirogova Str., 21018, Vinnytsya, Ukraine. \\ E-mail: poberezhets_vitalii@vnmu.edu.ua}

\section{KEYWORDS}

chronic obstructive pulmonary disease (COPD), comorbidities, sarcopenia, dyspnea, prognosis

\author{
Received: 24 February 2021 \\ Revised: 7 April 2021 \\ Accepted: 12 April 2021 \\ Pneumon 2021;34(1):6 \\ https://doi.org/10.18332/pne/135711
}

\section{INTRODUCTION}

Chronic obstructive pulmonary disease (COPD) as a systemic disease is usually present with numerous comorbidities. One of the most common overlapping diseases is a skeletal muscle dysfunction. According to the GOLD 2020 Report, skeletal muscle dysfunction is characterized by loss of muscle cells and dysfunction of the remaining cells ${ }^{1}$. This definition is similar to the definition of the sarcopenia from the latest revision of European Working Group on Sarcopenia in Older People (EWGSOP2), according to which sarcopenia should be defined as low muscle strength combined with low muscle quantity or quality². EWGSOP2 highlighted the role of sarcopenia as an important factor responsible for the impairment of daily physical activity, development of the cardiometabolic syndrome, and other complications. Presence of sarcopenia should be considered as being associated with an overall mortality and COPD-related mortality risk factor ${ }^{3}$, increased length of hospital stay, risk for hospitalization, lower probability of being discharged home ${ }^{4}$ and independently increasing hospital costs at hospital admission from 34\% to 58.5\% depending on the age of the population ${ }^{5}$. According to Goates et al. ${ }^{6}$, sarcopenia results in a great economic burden on the US healthcare system with total costs of hospitalizations amounting to more than US\$ 19 billion ${ }^{6}$.

Development of sarcopenia is a multifactorial process. EWGSOP2 determined factors that are related to the development of primary or secondary sarcopenia. According to EWGSOP2, the main cause for primary sarcopenia is ageing $^{2}$. Secondary sarcopenia is caused by such factors as diseases, inactivity, and poor nutrition. But the structure of predictive factors for sarcopenia among patients with COPD is still not clear. Taking into account an increase in systemic inflammation during an acute exacerbation, extrapulmonary manifestations and comorbidities, and progressive airflow limitation, may result in physical inactivity and other comorbidities acting as separate factors for sarcopenia ${ }^{2}$.

Our study aimed to determine the prevalence and predictive factors of sarcopenia development in COPD. 


\section{METHODS}

This study complied with the Declaration of Helsinki and received permission from the local ethics committees of the National Pirogov Memorial Medical University, Vinnytsya, Ukraine (No. 9 01.11.2018) and Medical University of Silesia, Katowice, Poland (PCM/0022/KB1/53/19). All recruited participants had confirmed COPD diagnosis based on Global Initiative for Chronic Obstructive Lung Disease (GOLD) guidelines and filled in an informed consent form. Patients with acute exacerbation of COPD and subjects who suffered from conditions that result in an inability to participate in research (disabling disorders of the musculoskeletal system, severe neurologic, cognitive and psychiatric disease, severe pulmonary hypertension, unstable cardiovascular disease, etc.) were excluded from the study.

In all, 190 COPD patients were recruited for the study (172 in Ukraine, 18 in Poland). They were classified according to GOLD guidelines into the following groups: A 1.6\% (3 patients), B 37.4\% (71 patients), C 38.4\% (73 patients), and D 22.6\% (43 patients).

All participants underwent a bioelectric impedance analysis to assess muscle quantity according to the percentage of muscle tissue in the body, fat-free mass index (FFMI) and skeletal muscle index (SMI). Additionally, we measured body mass index (BMI) and fat mass index (FMI) for each person. Skeletal muscle strength was assessed using hand-grip dynamometry of the dominant hand, and physical performance using gait speed by 6 -minute walk test (6MWT). Charlson Comorbidity Index (CCl) has been used as an effective tool to categorize comorbid conditions and to evaluate mortality risk ${ }^{7}$. Quality of life was evaluated using St. George's respiratory questionnaire (SGRQ) with further calculation of three components: symptoms (effect of respiratory symptoms, their frequency and severity), activity (activity limitation caused by breathlessness), and impact (social and psychological disturbances resulting from airways disease).

Symptoms of the disease were evaluated using the
COPD assessment test (CAT) and mMRC (Modified Medical Research Council) Dyspnea Scale.

EWGSOP2 criteria were used to diagnose sarcopenia. Sarcopenia was confirmed by documentation of low muscle strength and low muscle quantity. Additional documentation of low muscle performance was considered severe sarcopenia. The cut-off points for decreased skeletal muscle strength were hand-grip strength $<27 \mathrm{~kg}$ for men and $<16$ $\mathrm{kg}$ for women, for decreased physical performance gait speed $\leq 0.8 \mathrm{~m} / \mathrm{s}$, for low muscle quantity $\mathrm{SMl}<7.0 \mathrm{~kg} / \mathrm{m}^{2}$ for men and $<5.5 \mathrm{~kg} / \mathrm{m}^{2}$ for women ${ }^{2}$.

\section{Statistical analysis}

Our primary data and results are expressed as either mean \pm SD or frequency and percentage. Kolmogorov-Smirnov test was used to assess the normality of data distribution. Man-Whitney test and Independent Samples T-test was used to compare numerical parameters between patients with and without sarcopenia. Categorical variables (gender and comorbidity categories) were compared using Pearson's chisquared test between patients with and without sarcopenia. Binomial logistic regression analysis was applied to assess predictors for sarcopenia. A value of $p<0.05$ was considered statistically significant. SPSS Statistics 20.0 software package was used to perform all analyses.

\section{RESULTS}

Prevalence of sarcopenia among COPD patients is highlighted in Figure 1. We found that according to EWGSOP2 criteria, sarcopenia was present in 25.3\% (48 persons) of all COPD patients. It was present in $26.7 \%$ of males (46 patients) and $11.1 \%$ of females (2 patients). Severe sarcopenia was found in $6.3 \%$ of all patients (12 persons). All patients with severe sarcopenia were male.

Description of the demographic, clinical and body composition features of examined persons are presented in Table 1. COPD patients with sarcopenia were significantly older compared to COPD without sarcopenia $(72.9 \pm 9.7$ years

Figure 1. Prevalence of sarcopenia among COPD patients

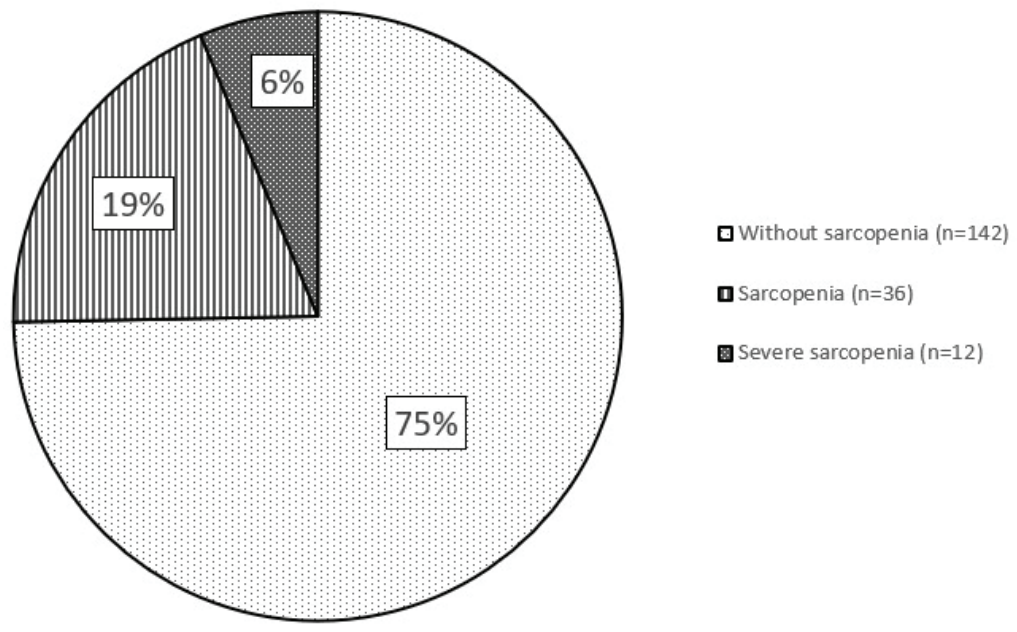


Table 1. Demographic, clinical characteristics and body composition of the patients $(N=190)$

\begin{tabular}{|c|c|c|c|c|}
\hline & All patients & $\begin{array}{c}\text { With } \\
\text { sarcopenia } \\
(n=48)\end{array}$ & $\begin{array}{c}\text { Without } \\
\text { sarcopenia } \\
(n=142)\end{array}$ & $\mathbf{p}$ \\
\hline \multicolumn{5}{|l|}{ Gender } \\
\hline Males & $172(90.5)$ & $46(95.8)^{a}$ & $126(88.7)$ & $<0.001$ \\
\hline Females & $18(9.5)$ & $2(4.2)^{a}$ & $16(11.3)$ & $<0.001$ \\
\hline \multicolumn{5}{|l|}{ Age (years) } \\
\hline Total & $66.1 \pm 10.5$ & $72.9 \pm 9.7^{a}$ & $63.8 \pm 9.8$ & $<0.001$ \\
\hline Males & $65.8 \pm 10.5$ & $72.9 \pm 9.9^{a}$ & $63.2 \pm 9.5$ & $<0.001$ \\
\hline Females & $68.6 \pm 10.7$ & $71.5 \pm 2.1$ & $68.2 \pm 11.3$ & 0.471 \\
\hline \multicolumn{5}{|l|}{ Clinical characteristics } \\
\hline Duration of COPD (years) & $5.2 \pm 3.1$ & $5.6 \pm 3.0$ & $5.0 \pm 3.2$ & 0.251 \\
\hline Smoking history (pack-years) & $36.4 \pm 21.0$ & $38.3 \pm 21.3$ & $35.7 \pm 21.0$ & 0.454 \\
\hline Acute exacerbation of COPD (per year) & $1.92 \pm 1.6$ & $2.4 \pm 1.3^{a}$ & $1.8 \pm 1.7$ & 0.001 \\
\hline CAT & $18.1 \pm 7.4$ & $21.2 \pm 6.3^{a}$ & $17.0 \pm 7.5$ & 0.001 \\
\hline $\mathrm{mMRC}$ & $2.45 \pm 1.1$ & $2.7 \pm 1.0$ & $2.4 \pm 1.1$ & 0.184 \\
\hline $\mathrm{FEV}_{1}(\%$ predicted $)$ & $45.7 \pm 17.5$ & $40.0 \pm 17.0^{a}$ & $47.7 \pm 17.3$ & 0.008 \\
\hline BODE index & $4.0 \pm 2.6$ & $5.7 \pm 2.6^{\mathrm{a}}$ & $3.5 \pm 2.3$ & $<0.001$ \\
\hline $\mathrm{CCl}$ & $2.6 \pm 1.4$ & $3.3 \pm 1.3^{a}$ & $2.3 \pm 1.3$ & $<0.001$ \\
\hline Myocardial infarction & $8(4.2)$ & $2(4.2)$ & $6(4.2)$ & 0.986 \\
\hline Congestive heart failure & $35(18.4)$ & $13(27.1)$ & $22(15.5)$ & 0.074 \\
\hline Peripheral vascular disease & $7(3.7)$ & $3(6.3)$ & $4(2.8)$ & 0.277 \\
\hline Cerebrovascular accident or transient ischemic attack & $5(2.6)$ & $1(2.1)$ & $4(2.8)$ & 0.785 \\
\hline Connective tissue disease & $3(1.6)$ & $1(2.1)$ & $2(1.4)$ & 0.747 \\
\hline Peptic ulcer disease & $5(2.6)$ & $2(4.2)$ & $3(2.1)$ & 0.445 \\
\hline Uncomplicated diabetes & $17(9.0)$ & $6(12.5)$ & $11(7.7)$ & 0.321 \\
\hline Diabetes with end-organ damage & $8(4.2)$ & $2(4.2)$ & $6(44.2)$ & 0.986 \\
\hline Moderate to severe chronic kidney disease & $4(2.1)$ & $1(2.1)$ & $3(2.1)$ & 0.990 \\
\hline Localized solid tumor & $3(1.6)$ & $1(2.1)$ & $2(1.4)$ & 0.747 \\
\hline Heart rate (pre 6MWT) (bpm) & $82.5 \pm 10.4$ & $75.0 \pm 9.8$ & $83.0 \pm 10.6$ & 0.474 \\
\hline Heart rate (post 6MWT) (bpm) & $97.4 \pm 9.9$ & $90.2 \pm 9.8$ & $97.9 \pm 10.1$ & 0.460 \\
\hline SaO2 (pre 6MWT) (\%) & $92.2 \pm 3.3$ & $93.1 \pm 3.2$ & $92.2 \pm 3.4$ & 0.821 \\
\hline $\mathrm{SaO} 2$ (post 6MWT) (\%) & $86.8 \pm 7.2$ & $90.3 \pm 7.0$ & $86.6 \pm 7.4$ & 0.665 \\
\hline Borg score (pre 6MWT) & $1.3 \pm 1.3$ & $2.1 \pm 1.4$ & $1.2 \pm 1.2$ & 0.068 \\
\hline Borg score (post 6MWT) & $4.6 \pm 2.8$ & $6.7 \pm 3.3^{a}$ & $4.1 \pm 2.4$ & 0.021 \\
\hline SGRQ Symptoms & $69.4 \pm 15.3$ & $73.6 \pm 11.5^{a}$ & $68.0 \pm 16.1$ & $<0.001$ \\
\hline SGRQ Activity & $66.1 \pm 20.7$ & $76.4 \pm 14.6^{a}$ & $62.7 \pm 21.3$ & 0.028 \\
\hline SGRQ Impact & $48.3 \pm 17.8$ & $57.1 \pm 15.1^{\mathrm{a}}$ & $45.3 \pm 17.7$ & $<0.001$ \\
\hline SGRQ Total & $57.3 \pm 16.2$ & $65.4 \pm 12.4^{a}$ & $54.6 \pm 16.4$ & $<0.001$ \\
\hline \multicolumn{5}{|l|}{ BMI $\left(\mathrm{kg} / \mathrm{m}^{2}\right)$} \\
\hline Males & $26.8 \pm 6.6$ & $23.2 \pm 5.7^{a}$ & $28.1 \pm 6.4$ & $<0.001$ \\
\hline Females & $28.6 \pm 7.9$ & $27.8 \pm 17.3$ & $28.7 \pm 7.1$ & 0.889 \\
\hline \multicolumn{5}{|l|}{ Hand-grip strength (kg) } \\
\hline Males & $33.1 \pm 12.0$ & $21.3 \pm 5.3^{a}$ & $37.2 \pm 10.8$ & $<0.001$ \\
\hline Females & $17.5 \pm 5.2$ & $12.5 \pm 3.5$ & $18.1 \pm 5.1$ & 0.155 \\
\hline
\end{tabular}


Table 1. Continued

\begin{tabular}{|c|c|c|c|c|}
\hline & All patients & $\begin{array}{c}\text { With } \\
\text { sarcopenia } \\
(n=48)\end{array}$ & $\begin{array}{c}\text { Without } \\
\text { sarcopenia } \\
(n=142)\end{array}$ & $\mathbf{p}$ \\
\hline \multicolumn{5}{|c|}{ Fat mass index $\left(\mathrm{kg} / \mathrm{m}^{2}\right)$} \\
\hline Males & $7.4 \pm 6.0$ & $5.6 \pm 4.3^{a}$ & $8.1 \pm 6.4$ & 0.014 \\
\hline Females & $10.9 \pm 6.5$ & $9.6 \pm 10.8$ & $11.1 \pm 6.3$ & 0.769 \\
\hline \multicolumn{5}{|c|}{ Visceral Fat } \\
\hline Males & $11.1 \pm 7.1$ & $8.4 \pm 6.5^{a}$ & $12.1 \pm 7.1$ & 0.002 \\
\hline Females & $9.11 \pm 6.3$ & $11.0 \pm 14.1$ & $8.9 \pm 5.6$ & 0.668 \\
\hline \multicolumn{5}{|c|}{ Skeletal muscle index $\left(\mathrm{kg} / \mathrm{m}^{2}\right)$} \\
\hline Males & $8.4 \pm 1.6$ & $6.7 \pm 1.4^{\mathrm{a}}$ & $9.0 \pm 1.2$ & $<0.001$ \\
\hline Females & $6.9 \pm 1.1$ & $5.2 \pm 0.3^{a}$ & $7.1 \pm 0.9$ & 0.009 \\
\hline \multicolumn{5}{|c|}{ Gait speed (m/s) } \\
\hline Males & $0.87 \pm 0.33$ & $0.61 \pm 0.32^{a}$ & $0.96 \pm 0.29$ & $<0.001$ \\
\hline Females & $0.71 \pm 0.33$ & $0.53 \pm 0.16$ & $0.75 \pm 0.35$ & 0.417 \\
\hline \multicolumn{5}{|c|}{ 6MWT distance (meters) } \\
\hline Males & $315.7 \pm 118.7$ & $221.3 \pm 116.3^{a}$ & $345.2 \pm 103.6$ & $<0.001$ \\
\hline Females & $256.6 \pm 120.7$ & $190 \pm 56.6$ & $271.3 \pm 128.3$ & 0.420 \\
\hline
\end{tabular}

Values are either frequency and percentage, $\mathrm{n}(\%)$, or mean \pm standard deviation. a Significant difference to 'Without sarcopenia' reference group.

vs $63.8 \pm 9.8$ years, $\mathrm{p}<0.001)$. COPD patients with sarcopenia had significantly more exacerbation in the last year compared to patients without sarcopenia $(2.4 \pm 1.3$ vs $1.8 \pm 1.7$, $\mathrm{p}=0.001)$. COPD patients with sarcopenia were more symptomatic than patients without sarcopenia, based on evaluation using a CAT questionnaire $(21.2 \pm 6.3$ vs $17.0 \pm 7.5$, $\mathrm{p}=0.001$ ) but the difference was not significant when an mMRC scale was used. COPD sarcopenia patients had a significantly lower FEV 1 compared to the control subjects $(40.0 \pm 17.0 \%$ of pred. vs $47.7 \pm 17.3 \%$ of pred., $p=0.008)$. Moreover, COPD patients with sarcopenia had a significantly worse quality of life according to all components of SGRQ: symptoms (73.6 \pm 11.5 vs $68.0 \pm 16.1, p<0.001)$, activity (76.4 \pm 14.6 vs $62.7 \pm 21.3, p=0.028)$, impact (57.1 \pm 15.1 vs $45.3 \pm 17.7, p<0.001)$ and total $(65.4 \pm 12.4$ vs $54.6 \pm 16.4$, $\mathrm{p}<0.001)$. COPD patients with sarcopenia had a significantly greater BODE index $(5.7 \pm 2.6$ vs $3.5 \pm 2.3, p<0.001)$ and higher $\mathrm{CCl}$ score $(3.3 \pm 1.3$ vs $2.3 \pm 1.3, \mathrm{p}<0.001)$ than those without sarcopenia. Body composition analysis showed that compared to the group without sarcopenia, male patients with sarcopenia had a significantly higher BMI $(23.2 \pm 5.7$ vs $28.1 \pm 6.4, p<0.001), F M l(5.6 \pm 4.3$ vs $8.1 \pm 6.4, p=0.014)$, SMI $(6.7 \pm 1.4$ vs $9.0 \pm 1.2, p<0.001)$, and visceral fat $(8.4 \pm 6.5$ vs $12.1 \pm 7.1, p=0.002)$. In addition, after assessing muscle strength and physical performance, male patients with sarcopenia showed significantly lower hand-grip strength $(21.3 \pm 5.3$ vs $37.2 \pm 10.8 \mathrm{~kg}, \mathrm{p}<0.001)$, gait speed $(0.61 \pm 0.32$ vs $0.96 \pm 0.29 \mathrm{~m} / \mathrm{s}, \mathrm{p}<0.001$ ) and shorter $6 \mathrm{MWT}$ distance
$(221.3 \pm 116.3$ vs $345.2 \pm 103.6 \mathrm{~m}, \mathrm{p}<0.001)$. Patients with sarcopenia also had a significantly higher Borg score (post $6 \mathrm{MWT})$ than persons without $(6.7 \pm 3.3$ vs $4.1 \pm 2.4, \mathrm{p}=0.021)$. Female patients with sarcopenia significantly differed from those without sarcopenia only in SMI $(5.2 \pm 0.3$ vs $7.1 \pm 0.9$ $\mathrm{kg} / \mathrm{m}^{2}, \mathrm{p}=0.009$ ).

Factors from Table 1 such as age, acute exacerbation of COPD, CAT, FEV , BODE index, CCl, Borg score (post 6MWT), SGRQ symptoms, SGRQ activity, SGRQ impact, BMI, fat mass index, visceral fat, gait speed, and 6MWT distance, were included in a binomial logistic regression model as possible predictors of sarcopenia. The binomial logistic regression analysis showed that risk of sarcopenia increases with higher level of visceral fat $(\mathrm{OR}=1.968 ; 95 \% \mathrm{Cl}: 1.250-3.100, \mathrm{p}=0.003)$, age (OR=1.228; 95\% Cl: 1.042-1.448, $\mathrm{p}=0.015)$, SGRQ activity score (OR=1.205; 95\% Cl: 1.024-1.417, $p=0.024)$ and lower BMI (OR=0.278; 95\% Cl: 0.126-0.614, p=0.002) (Table 2).

\section{Table 2. Factors associated with sarcopenia}

\begin{tabular}{lccc} 
& OR & $\mathbf{9 5 \%} \mathbf{~ C I}$ & $\mathbf{p}^{*}$ \\
\hline Age & 1.228 & $1.042-1.448$ & 0.015 \\
BMl & 0.278 & $0.126-0.614$ & 0.002 \\
Visceral fat & 1.968 & $1.250-3.100$ & 0.003 \\
SGRQ Activity & 1.205 & $1.024-1.417$ & 0.024
\end{tabular}

${ }^{*} p<0.05$ is statistically significant. 


\section{DISCUSSION}

We assessed the prevalence of sarcopenia among a group of COPD patients in Ukraine and Poland. We found that sarcopenia was present in $25.3 \%$ of COPD patients, and $6.3 \%$ of recruited COPD patients suffered from severe sarcopenia. Our results showed a slightly higher prevalence of sarcopenia compared to $21.6 \%$ given in a recent meta-analysis by Benz et al. ${ }^{8}$. There are several possible explanations for the slightly higher percentage of sarcopenia patients in our study: different disease severity and gender proportions of the study population and low adoption of pulmonary rehabilitation programs among COPD patients in our countries ${ }^{9}$.

We found that sarcopenia affected 46 male patients (26.7\%) and 2 female patients (11.1\%). Compared with those without sarcopenia, the group of COPD patients with sarcopenia was characterized by a significantly higher percentage of men (95.8\% vs 88.7\%, p <0.001) and a lower percentage of women (4.2\% vs $11.3 \%, p<0.001$ ). Severe sarcopenia was absent among females while it affected 12 male patients (7\% of all male patients). It is likely that our study's lower population of 18 women could have influenced the results. Despite this, our study results suggest that sarcopenia is more common in men with COPD. It is an interesting and new finding because published data on this matter are not clear. It was shown that among healthy people under the age of 70 years, sarcopenia was more common among females, while in the elderly group the situation was the opposite ${ }^{10}$. Others found that sarcopenia was comparatively common among male and female patients ${ }^{11,12}$.

According to our results, older age was strongly associated with the development of sarcopenia among COPD patients $(O R=1.228, p=0.015)$. Such an age role in the development of sarcopenia has been well studied and proven by many researchers from different countries 3,13-17. Muscaritoli et al. ${ }^{18}$ highlighted that development of agerelated sarcopenia is a complex process that results from physiological reductions of anabolic hormones levels, increased apoptotic activity in the skeletal muscles and systemic inflammation together with advanced oxidative stress and changes in the central nervous system. In a few studies, sarcopenia was found to be associated with older age and BODE score ${ }^{3,19}$. However, in our research we did not prove that the BODE index was a predictive factor for sarcopenia, however, we found that patients with sarcopenia had a significantly higher BODE index than patients without sarcopenia $(5.7 \pm 2.6$ vs $3.5 \pm 2.3, p<0.001)$ (Table 1$)$.

The level of visceral fat being the strongest factor associated with sarcopenia also could be explained by specific changes in the body caused by ageing. Couillard et al. $^{20}$ described this mechanism by alteration of steroid hormone profile in elderly men which results in fat redistribution from subcutaneous to visceral deposition. Furthermore, Furutate et al. ${ }^{21}$ showed that COPD patients with advanced stages of disease presented with excessive visceral fat despite the absence of obesity. According to their view, it was developed due to decrease physical inactivity among patients with severe COPD, leading to excess visceral fat accumulation.

According to our results, reduced daily physical activity based on SGRQ was another factor strongly associated with the development of sarcopenia among COPD patients $(\mathrm{OR}=1.968, \mathrm{p}=0.003)$. Discovering this association is extremely important because it explains the main mechanism of its appearance among persons with COPD. Low physical activity appears due to subjective feeling that restricts performing movement and leads to the appearance of sarcopenia. Such limitation is mainly based on airflow limitation, but it better reflects in the appearance of sarcopenia than $\mathrm{FEV}_{1}$ because different persons perceive in different ways the same level of airflow obstruction. Joppa et al. ${ }^{22}$ reported higher SGRQ physical activity of COPD patients with sarcopenic obesity than patients with normal body composition. Jones et al. ${ }^{12}$ already presented the same effect on skeletal muscle using specific questionnaires and accelerometer to evaluate physical activity. This finding improves our understanding of sarcopenia among COPD patients and requires further research.

We found a significant negative association between sarcopenia and $\mathrm{BMI}(\mathrm{OR}=0.278, \mathrm{p}=0.002)$. Similar associations between sarcopenia and gender, smoking status including current and ex-smokers, BMl among nursing home residents in Turkey were found by Tasar et al. ${ }^{23}$. Smoliner et al. ${ }^{24}$ after assessment of a great number of geriatric inpatients of an acute geriatric ward found that sarcopenia was significantly associated only with nutritional parameters presented by BMI and Mini Nutritional Assessment Short Form. Tsuchida et al. ${ }^{25}$ performed a prospective observational cohort study including patients with acute decompensated heart failure using dual-energy $\mathrm{X}$-ray absorptiometry and found a high prevalence of sarcopenia among the participants (52.6\% of study patients), they also found an association between sarcopenia and body mass index.

We did not show that frequent acute exacerbations of COPD were a predictive factor for sarcopenia, but their number per year was higher among patients with sarcopenia than in the control group $(2.4 \pm 1.3$ vs $1.8 \pm 1.7, p=0.001)$ (Table 1). Byun et al. ${ }^{3}$, Vestbo et al. ${ }^{12}$ and Jones et al. ${ }^{13}$ showed similar data about absence of associations between acute exacerbations of COPD and sarcopenia. While Spruit et al. ${ }^{26}$ showed that acute exacerbations of COPD lead to significantly reduced muscle force in COPD patients during and after acute exacerbations. Moreover, Vilaró et al. ${ }^{27}$ also showed that low muscle strength was strongly associated with the past and current hospital exacerbations of COPD.

Our research confirmed the results of many authors on the absence of significant difference in comorbidities between groups of patients based on sarcopenia presence ${ }^{12,16,17,24,25}$. The Charlson comorbidity index was not a predictive factor for sarcopenia, although patients with sarcopenia 
suffered from more comorbidities and had higher Charlson comorbidity index compared to the control group $(3.3 \pm 1.3$ vs $2.3 \pm 1.3, p<0.001$ ) (Table 1 ). We did not find associations with different categories of comorbidities as separate predictors, in contrast to our previous research where we revealed significant worse skeletal muscle impairment among COPD patients than coronary artery disease, despite several common predictive factors for sarcopenia ${ }^{28}$. Other authors presented data showing significant associations between comorbidities and sarcopenia. Tda et al. ${ }^{14}$ showed that COPD female patients with sarcopenia were significantly more likely to be affected with diabetes mellitus than male patients with osteoarthritis. Sousa et al. ${ }^{5}$ in their research proved the role of sarcopenia as an independent factor related to increasing hospitalization costs. They also found that sarcopenia usually affected males with greater Charlson comorbidity index score.

Patients with sarcopenia had significantly worse FEV than patients without sarcopenia $(40.0 \pm 17.0$ vs $47.7 \pm 17.3$, $\mathrm{p}=0.008$ ) (Table 1), however such airflow limitation was not a predictive factor for sarcopenia among COPD patients that confirmed the results of Costa et al. ${ }^{11}$. Nevertheless, in most studies, sarcopenia was associated with these factors. Vestbo et al. ${ }^{3}$ demonstrated that skeletal muscle quantity decreased with increasing severity of COPD. Thus, in GOLD stage 1 low FFMI was present in a quarter of the patients and GOLD stage 4 approximately 50\% of COPD patients had low FFMl ${ }^{3}$.

\section{Limitations}

Our study has some limitations. We used bioelectrical impedance analysis instead of 'gold standards' for noninvasive evaluation of skeletal muscle quantity such as magnetic resonance imaging (MRI) or computed tomography (CT). We choose this equipment because it was affordable and portable, taking into account settings in which our research has been performed. We used SGRQ to assess physical activity limitation instead of specific questionnaires such as the modified Minnesota Leisure-time Physical Activity Questionnaire, multisensory accelerometer and multiple physiological measures to calculate energy expenditure. Other limitations were the small study population, cross-sectional design, absence of assessments malnutrition of patients, the unbalanced composition of the population based on the GOLD groups and gender with the predominance of group $\mathrm{B}$ and $\mathrm{C}$ and male patients.

\section{CONGLUSIONS}

Sarcopenia affected almost every fourth COPD patient; it was present in 25.3\% of all patients with COPD. Only male COPD patients suffered from severe sarcopenia with a prevalence of 6.3\%. Sarcopenia was associated with older age, low body mass index, high level of visceral fat and limited physical activity.

\section{CONFLICTS OF INTEREST}

The authors have completed and submitted the ICMJE Form for Disclosure of Potential Conflicts of Interest and none was reported.

\section{FUNDING}

This work was supported by the 'PROM Programme International scholarship exchange of $\mathrm{PhD}$ students and academics for implementing a short form of education' (project No. POWR.03.03.00-IP.08-00-P13/18) and by a Silesian Medical University grant (KNW-1-103/N/9/K).

\section{ETHIGAL APPROVAL AND INFORMED CONSENT}

The study was approved by the local ethics committees at the National Pirogov Memorial Medical University, Vinnytsya, Ukraine (No. 9 01.11.2018) and Medical University of Silesia, Katowice, Poland (PCM/0022/KB1/53/19). All participants filled in an informed consent form for the study.

\section{DATA AVAILABILITY AND SHARING}

The data supporting this research is available from the authors on reasonable request.

\section{PROVENANGE AND PEER REVIEW}

Not commissioned; externally peer reviewed.

\section{REFERENGES}

1. Global Initiative for Chronic Obstructive Lung Disease. Global Strategy for the Diagnosis, Management, and Prevention of Chronic Obstructive Pulmonary Disease (2020 Report). 2020. Accessed February 24, 2021. https://goldcopd.org/goldreports/

2. Cruz-Jentoft AJ, Bahat G, Bauer J, et al. Sarcopenia: revised European consensus on definition and diagnosis. 2019;48(4):601. Age Ageing. 2019;48(1):16-31. doi:10.1093/ageing/afy169

3. Vestbo J, Prescott E, Almdal T, et al. Body mass, fatfree body mass, and prognosis in patients with chronic obstructive pulmonary disease from a random population sample: findings from the Copenhagen City Heart Study. Am J Respir Crit Care Med. 2006;173(1):79-83. doi:10.1164/rccm.200506-9690C

4. Sousa AS, Guerra RS, Fonseca I, Pichel F, Amaral TF. Sarcopenia and length of hospital stay. Eur J Clin Nutr. 2016;70(5):595-601. doi:10.1038/ejen.2015.207

5. Sousa AS, Guerra RS, Fonseca I, Pichel F, Ferreira S, Amaral TF. Financial impact of sarcopenia on hospitalization costs. Eur J Clin Nutr. 2016;70(9):1046-1051. doi:10.1038/ejcn.2016.73

6. Goates S, Du K, Arensberg MB, Gaillard T, Guralnik J, Pereira SL. Economic Impact of Hospitalizations in US Adults with Sarcopenia. J Frailty Aging. 2019;8(2):93-99. doi:10.14283/jfa.2019.10

7. Charlson ME, Pompei P, Ales KL, MacKenzie CR. A new method of classifying prognostic comorbidity in longitudinal studies: development and validation. J Chronic Dis. 1987;40(5):373- 
383. doi:10.1016/0021-9681(87)90171-8

8. Benz E, Trajanoska K, Lahousse L, et al. Sarcopenia in COPD: a systematic review and meta-analysis. Eur Respir Rev. 2019;28(154):190049. doi:10.1183/16000617.0049-2019

9. Garvey C, Spruit MA, Hill K, Pitta F, Shioya T. International COPD Coalition Column: pulmonary rehabilitation-reaching out to our international community. J Thorac Dis. 2013;5(3):343348. doi:10.3978/j.issn.2072-1439.2013.04.20

10. Kirchengast S, Huber J. Gender and age differences in lean soft tissue mass and sarcopenia among healthy elderly. Anthropol Anz. 2009;67(2):139-151. doi:10.1127/0003-5548/2009/0018

11. Costa TM, Costa FM, Moreira CA, Rabelo LM, Boguszewski CL, Borba VZ. Sarcopenia in COPD: relationship with COPD severity and prognosis. J Bras Pneumol. 2015;41(5):415421. doi:10.1590/S1806-37132015000000040

12. Jones SE, Maddocks M, Kon SS, et al. Sarcopenia in COPD: prevalence, clinical correlates and response to pulmonary rehabilitation. Thorax. 2015;70(3):213-218. doi:10.1136/thoraxjnl-2014-206440

13. Byun MK, Cho EN, Chang J, Ahn CM, Kim HJ. Sarcopenia correlates with systemic inflammation in COPD. Int J Chron Obstruct Pulmon Dis. 2017;12:669-675. doi:10.2147/COPD. S130790

14. Alexandre Tda S, Duarte YA, Santos JL, Wong R, Lebrão ML. Prevalence and associated factors of sarcopenia among elderly in Brazil: findings from the SABE study. J Nutr Health Aging. 2014;18(3):284-290. doi:10.1007/s12603-013-0413-0

15. Limpawattana P, Inthasuwan P, Putraveephong S, Boonsawat W, Theerakulpisut D, Sawanyawisuth K. Sarcopenia in chronic obstructive pulmonary disease: A study of prevalence and associated factors in the Southeast Asian population. Chron Respir Dis. 2018;15(3):250-257. doi:10.1177/1479972317743759

16. Martinez BP, Batista AK, Gomes IB, Olivieri FM, Camelier FW, Camelier AA. Frequency of sarcopenia and associated factors among hospitalized elderly patients. BMC Musculoskelet Disord. 2015;16:108. doi:10.1186/s12891-015-0570-x

17. Lee WJ, Liu LK, Peng LN, Lin MH, Chen LK; ILAS Research Group. Comparisons of sarcopenia defined by IWGS and EWGSOP criteria among older people: results from the I-Lan longitudinal aging study. J Am Med Dir Assoc. 2013;14(7):528. e1-528.e5287. doi:10.1016/j.jamda.2013.03.019

18. Muscaritoli M, Anker SD, Argilés J, et al. Consensus definition of sarcopenia, cachexia and pre-cachexia: joint document elaborated by Special Interest Groups (SIG) 'cachexia-anorexia in chronic wasting diseases' and 'nutrition in geriatrics'. Clin Nutr. 2010;29(2):154-159. doi:10.1016/j.clnu.2009.12.004

19. Munhoz da Rocha Lemos Costa T, Costa FM, Jonasson TH, Moreira CA, Boguszewski CL, Borba VZC. Body composition and sarcopenia in patients with chronic obstructive pulmonary disease. Endocrine. 2018;60(1):95-102. doi:10.1007/s12020-018-1533-4

20. Couillard C, Gagnon J, Bergeron J, et al. Contribution of body fatness and adipose tissue distribution to the age variation in plasma steroid hormone concentrations in men: the HERITAGE Family Study. J Clin Endocrinol Metab. 2000;85(3):1026-1031. doi:10.1210/jcem.85.3.6427

21. Furutate R, Ishii T, Wakabayashi R, et al. Excessive visceral fat accumulation in advanced chronic obstructive pulmonary disease. Int J Chron Obstruct Pulmon Dis. 2011;6:423-430. doi:10.2147/COPD.S22885

22. Joppa P, Tkacova R, Franssen FM, et al. Sarcopenic Obesity, Functional Outcomes, and Systemic Inflammation in Patients With Chronic Obstructive Pulmonary Disease. J Am Med Dir Assoc. 2016;17(8):712-718. doi:10.1016/j.jamda.2016.03.020

23. Tasar PT, Sahin S, Karaman E, et al. Prevalence and risk factors of sarcopenia in elderly nursing home residents. Eur Geriatr Med. 2015;6(3):214-219. doi:10.1016/j.eurger.2015.03.002

24. Smoliner C, Sieber CC, Wirth R. Prevalence of sarcopenia in geriatric hospitalized patients. J Am Med Dir Assoc. 2014;15(4):267-272. doi:10.1016/j.jamda.2013.11.027

25. Tsuchida K, Fujihara Y, Hiroki J, et al. Significance of Sarcopenia Evaluation in Acute Decompensated Heart Failure. Int Heart J. 2018;59(1):143-148. doi:10.1536/ihj.17-057

26. Spruit MA, Gosselink R, Troosters T, et al. Muscle force during an acute exacerbation in hospitalised patients with COPD and its relationship with CXCL8 and IGF-I. Thorax. 2003;58(9):752-756. doi:10.1136/thorax.58.9.752

27. Vilaró J, Ramirez-Sarmiento A, Martínez-Llorens JM, et al. Global muscle dysfunction as a risk factor of readmission to hospital due to COPD exacerbations. Respir Med. 2010;104(12):1896-1902. doi:10.1016/j.rmed.2010.05.001

28. Poberezhets V, Mostovoy Y, Demchuk H. Skeletal muscle dysfunction in patients with chronic obstructive pulmonary disease and coronary artery disease. Eur Respir J. 2015;46(suppl 59):PA662. doi:10.1183/13993003.congress-2015.PA662 